\title{
Shortened time interval between colorectal cancer diagnosis and risk testing for hereditary colorectal cancer is not related to higher psychological distress
}

\author{
K. M. Landsbergen · J. B. Prins • H. G. Brunner • \\ N. Hoogerbrugge
}

Published online: 19 September 2010

(c) The Author(s) 2010. This article is published with open access at Springerlink.com

\begin{abstract}
Current diagnostic practices have shortened the interval between colorectal cancer (CRC) diagnosis and genetic analysis for Lynch syndrome by MSI-testing. We studied the relation of time between MSI-testing since CRC diagnosis (MSI-CRC interval) and psychological distress. We performed a cross-sectional study in 89 patients who had previously been treated for CRC. Data were collected during MSI-testing after genetic counseling. Psychological distress was measured with the IES, the SCL-90 and the POMS; social issues with the ISS, ISB and the ODHCF. The median time of MSI-CRC interval was 24 months (range $0-332$ ), with $23 \%$ of the patients diagnosed less than 12 months and $42 \%$ more than 36 months prior to MSI-testing. In $34 \%$ of the patients cancer specific distress was high (IES scores $>26$ ). Mean psychopathology (SCL-90) scores were low, mean mood states (POMS) scores were moderate. Interval MSI-CRC was not related to psychological distress. High cancer specific distress was reported by $24 \%$ of patients diagnosed with CRC less than 12 months ago versus 39 and $35 \%$ by those diagnosed
\end{abstract}

K. M. Landsbergen · H. G. Brunner - N. Hoogerbrugge Department of Human Genetics, Raboud University Nijmegen Medical Centre, Geert Grooteplein zuid 10, 6525 GA Nijmegen, The Netherlands

\section{J. B. Prins}

Department of Medical Psychology, Raboud University Nijmegen Medical Centre, Geert Grooteplein zuid 10, 6525 GA Nijmegen, The Netherlands

K. M. Landsbergen ( $\square)$

849 Department of Human Genetics, Radboud University

Nijmegen Medical Centre, P.O. Box 9101, 6500 HB Nijmegen,

The Netherlands

e-mail: k.landsbergen@antrg.umcn.nl between 12 and 36 months and more than 36 months ago respectively. Distress was positively related to female gender $(P=0.04)$, religiousness $(P=0.01)$, low social support $(P=0.02)$ and difficulties with family communication $(P<0.001)$. Shortened time interval between CRC diagnosis and MSI-testing is not associated with higher psychological distress. Females, religious persons, those having low social support and those reporting difficulties communicating hereditary colorectal cancer with relatives are at higher risk for psychological distress.

Keywords Colorectal cancer - Genetic testing - Lynch syndrome $\cdot$ MSI-analysis · Psychological distress · Time

\section{Introduction}

In The Netherlands more than 11,000 people are diagnosed with colorectal cancer each year [1]. This means that around 1 in 20 Dutch people will develop colorectal cancer in their lifetime. The majority of colorectal cancer patients have sporadic disease and only a minority of colorectal cancers has a genetic cause. One well-described colorectal cancer genetic syndrome is Lynch syndrome which is estimated to account for 3-5\% of all colorectal cancer $[2,3]$. Lynch syndrome is an autosomal dominant inherited disorder characterized by an increased risk to develop colorectal cancer (60-90\% lifetime risk) and an increased risk of extra-colonic tumors, especially endometrial cancer (25-70\% lifetime risk); the age at diagnosis for colorectal cancer is most often between 41 and 54 years, for endometrial cancer between 45 and 50 years [2,3]. Lynch syndrome mutation carriers are advised to have regular colorectal screening, starting at the age of 25 , with a maximum interval of 24 months between each examination 
[4]. Regular surveillance reduces morbidity and mortality by $65 \%$ over 15 years in previously unaffected relatives and also reduces the risk of a second colorectal cancer in patients [5]. Lynch syndrome is caused by mutations in one of the mismatch repair (MMR) genes and is characterized by tumors that show microsatellite instability (MSI), which is found in more than 90 percent of tumors from patients with Lynch syndrome [2]. In current practice, MSI analysis is used as a pre screening tool selecting families for further analysis of MMR gene defects [6].

Undoubtedly cancer diagnosis is a traumatic life event [7]. Genetic counseling and testing for hereditary cancer can also be a strong stressor [8]. It may cause uncertainty about future cancer which may lead to an increased level of cancer specific distress, activating intrusion or avoidance or both [9]. After genetic counseling, greater awareness of the increased risk of second cancer and of the genetic contribution to an increased risk of cancer for their children may lead to an increased level of cancer specific distress [8]. Additionally a positive genetic test result may reactivate or aggravate distress related to cancer diagnosis and treatment [10].

Studies, which address the psychological impact of genetic counseling and testing for hereditary colorectal cancer in healthy individuals or given time after cancer diagnosis, generally indicate that genetic information does not result in adverse psychological outcomes in the long term [11-14]. However, due to a change in various protocols, the time between colorectal cancer diagnosis and genetic counseling and testing for Lynch syndrome is decreasing. This is partly due to MSI testing by pathologists, for instance in tissue of patients diagnosed before age 50 or from patients with a second CRC before age 70 [15]. A striking psychological difference with former practice is that these patients are confronted with a possibly hereditary predisposition for Lynch syndrome coincident with treatment for CRC. Little is known about the psychosocial impact of genetic testing in patients with a recent diagnosis of colorectal cancer.

The aim of the current study is to investigate whether high levels of overall psychological distress are present during MSI-testing and whether these levels are correlated with time since colorectal cancer diagnosis. For that purpose we use both the Impact of Event Scale (IES), the Symptom Checklist-90 and the Profile Of Mood States (POMS); the IES because more recently diagnosed patients might be more vulnerable to reactivation or aggravation of cancer specific distress and the SCL-90 and the POMS to measure general psychological distress during the past week. Concerns of heredity mediated distress and cancer specific distress may affect both the overall level of distress. However, this cannot be distinguished in our sample.

\section{Materials and methods}

Study design and procedure

A cross-sectional study was performed to determine psychological distress in patients previously treated for colorectal cancer just after initiation of MSI testing. All patients visited the Department of Clinical Genetics of the Radboud University Medical Centre Nijmegen in the Netherlands. Before MSI-testing was started, comprehensive genetic counseling took place to ensure that the patient understands the implications of the MSI-test. MSI-testing was performed after informed consent of the patient. Inclusion criteria of the study were (1) patients with colorectal cancer (2) fulfilling one of the Bethesda criteria for MSI-testing [4] and (3) having a CRC to be tested for MSI. Patients were excluded in case of (1) previous MSI-testing or (2) current treatment for psychiatric disorders. In every patient medical history for psychiatric disorders and former and current psychiatric treatment is taken. From Augustus 2007 to September 2009, 191 eligible patients were approached by their genetic counselor $(n=14)$ to participate the study. Of these potential eligible patients 16 patients considered participating too stressful, three patients were in a terminal phase and two patients had already received the MSI-test result. Four patients were in current psychiatric treatment and therefore excluded from study participation. Of 77 from the remaining 81 patients personal reasons for nonparticipation were retrieved being "not interested" (64\%), "too busy" (25\%) and "just forgotten" (11\%). Finally, written informed consent was obtained from 89 participants in accordance to the rules of the Committee on Research Involving Human Subjects, Region ArnhemNijmegen in the Netherlands. Psychological and social data were collected by validated questionnaires immediately after initiation of MSI-testing, still before MSI-test disclosure. Information regarding family cancer history was retrieved from medical records.

\section{Measures}

\section{Demographic and colorectal cancer information}

Data were obtained on age, gender, marital and parental status, education, religion, cancer status and on having a first degree relative with cancer.

Psychological distress

\section{Cancer specific distress}

The Impact of Event Scale (IES) [16, 17] was geared towards colorectal cancer as distressing event (scoring 
$0,1,3,5)$. A total score of $9-25$ reflects moderate adaptation difficulties, a score above 26 indicates serious adaptation difficulties [18]. The IES is widely used as a measure of cancer specific distress within the context of genetic counselling and testing for hereditary cancer $[19,20]$.

\section{Psychopathology}

The Symptom Checklist-90 (SCL-90) is a 90-item indicator for psychopathology. A SCL-90 score above 160 is indicative for serious psychological complaints, a score above 200 is indicative for a psychiatric disorder [21].

\section{Mood states}

The Profile of Mood States-Brief (POMS-SF) [22] measures depression (range 0-32), anger (range 0-28), fatigue (range 0-24), tension (range 0-24) and vigour (range $0-20)$.

\section{Social support}

The Inventory for Social Support (ISS) [23] comprises 3 scales: potential emotional trust (range 5-20), actual trust (range 3-12) and visits (range 2-8).

\section{Family communication}

Family communication was assessed with an adaptation of the Openness to Discuss Hereditary Cancer in the Family Scale (ODHCF) [24, 25]. Openness was assessed with the item "I discuss hereditary colorectal cancer with my partner, children, parents, brothers, sisters, uncles and aunts, nephews and nieces, respectively, i.e. never (1), rarely (2), sometimes (3) and often (4)". Family communication difficulties and in need of help were assessed similarly (range $7-24)$.

\section{Statistical analysis}

The SPSS 16.0 statistical package was used to analyze the data. Correlations between cancer specific distress (IES), psychopathology (SCL-90) and mood states (POMS) were assessed by the Spearman' Rank Correlation. Time between colorectal cancer (CRC) diagnosis and the initiation of MSI-testing was defined as "Interval MSI-CRC" and measured in months. Interval MSI-CRC was divided in 3 categories: shortly after CRC diagnosis $(<12$ months after diagnosis), recuperating from cancer treatment (12-36 months after diagnosis) and diagnosed with cancer longer ago ( $>36$ months after diagnosis). Interrelations between the interval CRC-MSI, various other personal variables (i.e. gender, marital and parental status, religion, cancer and cancer treatment related, having a first degree relative with cancer, social support, family communication) and cancer specific distress were analyzed. The IES was dichotomized, where 26 was used as cut-off value for clinically high levels of psychological distress [16]. Multivariate logistic regression analysis was performed for all variables that were analyzed in univariate analysis and were statistically significant correlated with the IES $>26$, with stepwise removal of non-significant variables. Odds ratios (OR's) were calculated to describe associations between personal characteristics and the IES $>26$ and presented with their $95 \%$ confidence intervals $(95 \% \mathrm{CI})$. $P$-values $<0.05$ were considered statistically significant (two-tailed).

\section{Results}

Study sample

From August 2007 till September 2009, 193 patients with a history of colorectal cancer were approached by their genetic counselor after genetic counseling and initiation of MSI analysis. Eighty-nine patients were included (response rate $46 \%$ ). No significant differences were found regarding sociodemographic and colorectal cancer related characteristics between participants and non-participants.

Sociodemographic and colorectal cancer related characteristics

Most participants were female (64\%), married or cohabiting (83\%), had children (88\%) and considered themselves religious $(72 \%)$. The median age at CRC diagnosis was 49 years with the youngest patient diagnosed at age 24 years. The median age at initiating MSI-testing was 55 years (range 32-85 years). The median time of the CRC-MSI interval was 24 months (range 0-332 months). So the range in time since cancer diagnosis was large, with $23 \%$ of the patients diagnosed less than 12 months and $42 \%$ of the patients diagnosed with cancer more than 36 months ago. Colorectal cancer related characteristics of the study sample are provided in Table 1.

\section{Social characteristics}

Social support and family communication characteristics are provided in Table 2. Mean social support scores were comparable to those of a norm group in the Dutch population [23]. The mean family communication openness score was moderate; mean family communication difficulties and in need of help scores were low. Of the males, 
Table 1 Colorectal cancer (CRC) related characteristics of the study sample

\begin{tabular}{|c|c|c|}
\hline & \multicolumn{2}{|c|}{$\begin{array}{l}\text { Patients with a history } \\
\text { of CRC }(n=89)\end{array}$} \\
\hline & $n$ & $\%$ \\
\hline \multicolumn{3}{|l|}{ Lynch syndrome alert } \\
\hline $\mathrm{CRC}<50$ years & 52 & 58 \\
\hline $\begin{array}{l}2 \times \text { Lynch syndrome related } \\
\text { tumor }^{\mathrm{a}}<70 \text { years }\end{array}$ & 37 & 42 \\
\hline First degree relative with cancer & 65 & 73 \\
\hline \multicolumn{3}{|l|}{ Cancer treatment } \\
\hline Surgery without adjuvant therapy & 36 & 40 \\
\hline Surgery with chemotherapy (CT) & 44 & 49 \\
\hline Surgery with radiotherapy (RT) & 21 & 24 \\
\hline Surgery with both CT and RT & 12 & 13 \\
\hline \multicolumn{3}{|l|}{ Time between CRC and MSI-analysis } \\
\hline$<12$ months & 21 & 23 \\
\hline $12-36$ months & 31 & 35 \\
\hline$>36$ months & 37 & 42 \\
\hline
\end{tabular}

${ }^{a}$ Endometrial cancer and carcinomas of stomach, small bowl, biliary tract, brains, sebaceous gland, upper urinary tract and ovaries

Table 2 Psychological and social characteristics of the study sample

\begin{tabular}{|c|c|c|}
\hline & \multicolumn{2}{|c|}{ Patients with a history of CRC $(n=89)$} \\
\hline & Mean & SD \\
\hline \multicolumn{3}{|l|}{ Mood states $^{\mathrm{a}}$} \\
\hline Depression & 2.6 & 4.8 \\
\hline Anger & 2.7 & 4.5 \\
\hline Fatigue & 5.4 & 5.7 \\
\hline Tension & 3.2 & 4.4 \\
\hline Vigor & 10.7 & 4.7 \\
\hline Psychopathology ${ }^{b}$ & 122.8 & 30.6 \\
\hline Social anxiety ${ }^{c}$ & 111.4 & 15.3 \\
\hline \multicolumn{3}{|l|}{ Social support ${ }^{\mathrm{d}}$} \\
\hline Potential trust & 17.1 & 3.3 \\
\hline Actual trust & 7.2 & 1.9 \\
\hline Visits & 6.2 & 1.2 \\
\hline \multicolumn{3}{|c|}{ Family communication $^{\mathrm{e}}$} \\
\hline Openness & 14.4 & 4.1 \\
\hline Difficulties & 8.3 & 4.9 \\
\hline In need of help & 7.0 & 5.0 \\
\hline
\end{tabular}

${ }^{\mathrm{a}}$ POMS brief

b SCL-90

c ISS

d ISS

e $\mathrm{ODHCF}$

$22 \%$ reported difficulties regarding family communication about hereditary colorectal cancer versus $55 \%$ of the females. Regarding the item "in need of help", $25 \%$ of the males versus $46 \%$ of the females felt the need for help in discussing hereditary cancer with the family.

Levels of psychological distress

The mean level of psychological distress (IES) was 16.90 (SD 21.7). More than one-third of the study sample reported clinically elevated levels of distress (IES $>26$ ), of whom $39 \%$ females and $25 \%$ males. Significantly more patients who considered themselves religious reported an IES level above 26 compared to non-religious patients (41\% vs. $16 \%, P=0.04$ ). Patients who reported difficulties regarding family communication were more likely to report an IES level above $26(47 \%)$ than patients with good family communication $(24 \%)(P=0.02)$. Of the patients diagnosed with colorectal cancer less than 12 months ago fewer reported high psychological distress (24\%), than patients diagnosed between 12-36 months ago (39\%) and those diagnosed more than 3 years ago $(35 \%)$.

Relations with the total level of psychological distress (IES-total)

In Table 3 Spearman rank correlations between patient's personal sociodemographic/psychosocial characteristics and the total level of psychological distress are shown. The total level of psychological distress was significantly correlated with gender $(P=0.04)$, being religious $(P=0.01)$, social support visits $(P=0.02)$, family communication difficulties $(P<0.001)$ and family communication in need of help $(P=0.009)$. No relation was found of time between CRC diagnosis and MSI-testing with levels of psychological distress.

Relations with high levels of psychological distress (IES > 26)

Being religious and family communication difficulties were significantly correlated with high levels of psychological distress, OR 0.28 (95\% CI $0.09-0.91 ; P=0.03$ ) and OR 0.34 (95\% CI $0.14-0.85 ; P=0.02)$, respectively. Multivariate logistic regression analysis showed that the presence of high psychological distress was independently related to family communication difficulties, OR 0.37 (95\% CI 0.14-0.95; $P=0.04$ ).

Psychopathology and mood states

Psychopathology and mood states scores of the study sample are shown in Table 2. The mean psychopathology scores of our participants were low [21], while three patients reported high levels of psychopathology (mean 229, range 209-255). Mean POMS subscales scores were 
Table 3 Correlations with the level of colorectal cancer specific distress (IES-total)

\begin{tabular}{ll}
\hline Patient's characteristics & $\begin{array}{l}\text { Colorectal cancerdistress } \\
\mathrm{Rs}^{\mathrm{a}}\end{array}$ \\
\hline Sociodemographic & \\
Gender & $0.218^{*}$ \\
Married or cohabiting & -0.029 \\
Having children & 0.014 \\
Being religious & $0.272^{* *}$ \\
Colorectal cancer related & \\
Age at diagnosis & -0.081 \\
Cancer treatment & -0.007 \\
First degree relative with cancer & -0.110 \\
Genetic risk assessment & \\
Months between CRC and MSI & -0.005 \\
Interval CRC-MSI in 3 time categories & -0.029 \\
Psychological characteristics & \\
Depression & $0.447^{* *}$ \\
Anger & $0.348^{* *}$ \\
Fatique & $0.287^{* *}$ \\
Tension & $0.462^{* *}$ \\
Vigor & $-0.279 * *$ \\
Psychopathology & $0.532^{* *}$ \\
Social anxiety & -0.080 \\
Social support & \\
Potential trust & -0.178 \\
Actual trust & 0.119 \\
Visits & $-0.243^{*}$ \\
Family communication & \\
Openness & \\
Difficulties & \\
In need of help & \\
\hline Rs, Spearman Rank correlation & \\
& \\
\hline & \\
\hline &
\end{tabular}

higher compared to patients with gynaecological cancer of whom the majority experienced stage I disease [26] but lower than patients with cancer awaiting bone marrow transplantation [27]. No statistically significant correlations were found between "Interval MSI-CRC" and the SCL-90 or between "Interval MSI-CRC" and the "POMS subscales". The SCL-90 and the POMS correlated significantly with the IES and to avoid duplication of results we decided not to report all retrieved data.

\section{Discussion}

The findings suggest that the level of psychological distress is not related to time between colorectal cancer diagnosis and MSI testing. In fact, patients diagnosed with colorectal cancer less than 1 year ago reported less psychological distress than patients diagnosed with cancer longer ago. Contemplation and consideration of the cancer is more likely to occur once active treatment for cancer in the hospital is over. Experiencing intrusive thoughts may be a signal that people are working through the implications of the cancer [28]. In line with this, a previous study showed that $15 \%$ of patients with breast cancer became distressed not until after end of treatment, in the reentry phase [29].

Our study results indicate that in general genetic testing during the treatment phase of CRC may not be harmful for patients with CRC. However, approximately one-third of the patients reported clinically high levels of psychological distress. The prevalence rate of high cancer distress is higher than the $3-24 \%$ reported in the literature $[8,13,19$, 30-32]. This might be explained by selection bias whereby individuals who chose to participate in the study were more distressed compared to those who did not.

We analysed which patients were at highest risk for distress and found three risk factors: gender, religion and reduced social support including impaired family communication. In our study female patients reported higher levels of psychological distress than male patients. This fits with many other studies in which gender is found to be related to psychological distress upon genetic testing [33] and with a review which demonstrated that female patients with colorectal cancer are most vulnerable for hereditary cancer genetic testing related distress [34]. Unexpectedly, religious patients were found to report the highest levels of psychological distress. Previous studies showed that patients use spiritual and religious resources to understand and cope with morbidity and mortality [35] and that this helps people cope with genetic uncertainty [36]. We note that there are positive and negative patterns of religious coping [35] and in this study we did not measure distinct religious coping patterns. It might be that in our study sample negative religious coping patterns dominated. In a study with participants tested for BRCAl mutations no significant associations between religiosity and psychological distress were observed [37]. We conclude to this point that religious coping in the context of genetic testing is an area in which more studies are needed. Finally, low social support and difficulties with family communication were related to higher levels of psychological distress. This is consistent with a study among colorectal cancer survivors undergoing genetic testing for Lynch syndrome in which higher levels of cancer related distress was related to less social support [38]. Genetic testing and hereditary cancer are family matters. Family system characteristics may influence the way the individual and the family as a whole copes with hereditary cancer [39]. Our data showed 
that difficulties and being in need of help regarding family communication about hereditary cancer were related to psychological distress. Participants more frequently reported cancer related distress when they perceived family communication about hereditary cancer as inhibited [40]. The quality of communication is of paramount importance where open family communication may be an important buffer against hereditary cancer distress [40]. Patients who report difficulties regarding communicating hereditary cancer with the family seems vulnerable to high levels of psychological distress. Questioning family communication can identify these patients. Former experiences with cancer may also play an role in genetic testing responses [41]. Experiences with cancer in the family may result in an increased psychological vulnerability during genetic testing for hereditary cancer [25]. However, we found no relation between either cancer treatment or having a first degree relative with cancer and the level of psychological distress. The latter finding is in contrast with a study which showed that having a first degree relative with colorectal disease predicted a higher level of distress about colorectal cancer [42]. Previous studies found being unmarried [43] and having children [33] as predictors of psychological distress related to genetic testing for hereditary cancer. In our study sample however, no correlations were found between marital or parental status and the level of psychological distress.To our knowledge, this is the first study that measures psychological distress in relation to time between colorectal cancer diagnosis and genetic testing for hereditary cancer. Moreover, this is the first study measuring psychological distress at the time of testing for being at high risk for Lynch syndrome by MSI-analysis. A point of attention is that response rate was low and our study sample may reflect selection-bias. Although demographic and cancer related characteristics of the participants and the non-participants did not differ significantly, psychological characteristics of the non-responders were not obtained. Other limitations of the study is the relatively small sample size and the crosssectional design. To determine the causal effect of MSItesting on levels of psychological distress a prospective randomized study design is preferred.

Our results suggest that high levels of psychological distress are not related to the duration of the time period between MSI-testing since CRC diagnosis. We carefully conclude that patients who are either female, religious, having low social support or those reporting difficulties in communicating hereditary colorectal cancer with relatives are at higher risk for psychological distress.

Acknowledgments We are very grateful to the participants for their valuable contribution to the study, to Riki Willems for identification of potential participants and to the genetic counselors for their collaboration. The study was supported by a grant of the Netherlands Digestive Diseases Foundation (SWO 05-07).
Open Access This article is distributed under the terms of the Creative Commons Attribution Noncommercial License which permits any noncommercial use, distribution, and reproduction in any medium, provided the original author(s) and source are credited.

\section{References}

1. VIKC Colorectal Cancer Incidence in 2009 in The Netherlands. (2009) http://nkr.ikcnet.nl

2. Lynch HT, De.La Chapelle A (2003) Hereditary colorectal cancer. N Engl J Med 348:919-932

3. Vasen HF, Wijnen JT, Menko FH et al (1996) Cancer risk in families with hereditary nonpolyposis colorectal cancer diagnosed by mutation analysis. Gastroenterology 110:1020-1027

4. Vasen HF, Moslein G, Alonso A et al (2007) Guidelines for the clinical management of Lynch syndrome (hereditary non-polyposis cancer). J Med Genet 44:353-362

5. Jarvinen HJ, Aarnio M, Mustonen H et al (2000) Controlled 15year trial on screening for colorectal cancer in families with hereditary nonpolyposis colorectal cancer. Gastroenterology 118:829-834

6. VKGN Vereniging Klinische Genetica Nederland. (2008) www.vkgn.nl

7. Jadoulle V, Rokbani L, Ogez D et al (2006) Coping and adapting to breast cancer: a six-month prospective study. Bull Cancer 93:E67-E72

8. Bjorvatn C, Eide GE, Hanestad BR et al (2009) Intrusion and avoidance in subjects undergoing genetic investigation and counseling for hereditary cancer. Support Care Cancer 17:13711381

9. Neville K (1998) The relationships among uncertainty, social support, and psychological distress in adolescents recently diagnosed with cancer. J Pediatr Oncol Nurs 15:37-46

10. Dorval M, Patenaude AF, Schneider KA et al (2000) Anticipated versus actual emotional reactions to disclosure of results of genetic tests for cancer susceptibility: findings from p53 and BRCA1 testing programs. J Clin Oncol 18:2135-2142

11. Bleiker EM, Menko FH, Kluijt I et al (2007) Colorectal cancer in the family: psychosocial distress and social issues in the years following genetic counselling. Hered Cancer Clin Pract 5:59-66

12. Claes E, Denayer L, Evers-Kiebooms G et al (2004) Predictive testing for hereditary non-polyposis colorectal cancer: motivation, illness representations and short-term psychological impact. Patient Educ Couns 55:265-274

13. Gritz ER, Peterson SK, Vernon SW et al (2005) Psychological impact of genetic testing for hereditary nonpolyposis colorectal cancer. J Clin Oncol 23:1902-1910

14. Meiser B, Collins V, Warren R et al (2004) Psychological impact of genetic testing for hereditary non-polyposis colorectal cancer. Clin Genet 66:502-511

15. The Dutch Association of Comprehensive Cancer Centres Dutch Guideline Hereditary Colorectal Cancer. http://www.oncoline.nl. 9-1-2008

16. Horowitz M, Wilner N, Alvarez W (1979) Impact of event scale: a measure of subjective stress. Psychosom Med 41:209-218

17. van der Ploeg E, Mooren TT, Kleber RJ et al (2004) Construct validation of the Dutch version of the impact of event scale. Psychol Assess 16:16-26

18. Hatcher MB, Fallowfield L, A'Hern R (2001) The psychosocial impact of bilateral prophylactic mastectomy: prospective study using questionnaires and semistructured interviews. BMJ 322:76

19. Reichelt JG, Heimdal K, Moller P et al (2004) BRCA1 testing with definitive results: a prospective study of psychological distress in a large clinic-based sample. Fam Cancer 3:21-28 
20. Thewes B, Meiser B, Hickie IB (2001) Psychometric properties of the impact of event scale amongst women at increased risk for hereditary breast cancer. Psychooncology 10:459-468

21. Arindell WA, Ettema JHM (1986) SCL-90, Handleiding bij een multidimensionele psychopathologie-indicator. Swets \& Zeitlinger B.V, Amsterdam

22. McNair DM, (Dutch translation by Wald \& Mellenbergh 1990) (1971) Manual for the profile of mood states. Educational and Industrial Testing Service, San Diego

23. van Dam-Baggen R, Kraaimaat FW (1992) Inventory social support (ISB). Gedragstherapie 25:27-46

24. Mesters I, van den Borne H, McCormick L et al (1997) Openness to discuss cancer in the nuclear family: scale, development, and validation. Psychosom Med 59:269-279

25. van Oostrom I, Meijers-Heijboer H, Lodder LN et al (2003) Long-term psychological impact of carrying a BRCA1/2 mutation and prophylactic surgery: a 5-year follow-up study. J Clin Oncol 21:3867-3874

26. Gould RV, Brown SL, Bramwell R (2010) Psychological adjustment to gynaecological cancer: patients' illness representations, coping strategies and mood disturbance. Psychol Health 25(5):633-646

27. Baker F, Denniston M, Zabora J et al (2002) A POMS short form for cancer patients: psychometric and structural evaluation. Psychooncology 11:273-281

28. Helgeson VS, Reynolds KA, Tomich PL (2006) A meta-analytic review of benefit finding and growth. J Consult Clin Psychol 74:797-816

29. Henselmans I, Helgeson VS, Seltman H et al (2010) Identification and prediction of distress trajectories in the first year after a breast cancer diagnosis. Health Psychol 29:160-168

30. van Oostrom I, Meijers-Heijboer H, Duivenvoorden HJ et al (2007) The common sense model of self-regulation and psychological adjustment to predictive genetic testing: a prospective study. Psychooncology 16:1121-1129

31. Reichelt JG, Moller P, Heimdal K et al (2008) Psychological and cancer-specific distress at 18 months post-testing in women with demonstrated BRCA1 mutations for hereditary breast/ovarian cancer. Fam Cancer 7:245-254

32. Schlich-Bakker KJ, Warlam-Rodenhuis CC, van Echtelt $\mathrm{J}$ et al (2006) Short term psychological distress in patients actively approached for genetic counselling after diagnosis of breast cancer. Eur J Cancer 42:2722-2728

33. DudokdeWit AC, Tibben A, Duivenvoorden HJ et al (1998) Predicting adaptation to presymptomatic DNA testing for late onset disorders: who will experience distress? Rotterdam Leiden genetics workgroup. J Med Genet 35:745-754

34. Landsbergen KM, Prins JB, Brunner HG et al (2009) Genetic testing for Lynch syndrome in the first year of colorectal cancer: a review of the psychological impact. Fam Cancer 8:325-337

35. Koenig HG, McCullough ME, Larson DB (2001) Handbook of religion and health. Oxford University Press, Oxford, New York

36. White MT (2009) Making sense of genetic uncertainty: the role of religion and spirituality. Am J Med Genet C Semin Med Genet 151C:68-76

37. Kinney AY, Coxworth JE, Simonson SE et al (2009) Religiosity, spirituality, and psychological distress in African-Americans at risk for having a hereditary cancer predisposing gene mutation. Am J Med Genet C Semin Med Genet 151C:13-21

38. Esplen MJ, Madlensky L, Aronson M et al (2007) Colorectal cancer survivors undergoing genetic testing for hereditary nonpolyposis colorectal cancer: motivational factors and psychosocial functioning. Clin Genet 72:394-401

39. Wagner A, Tops C, Wijnen JT et al (2002) Genetic testing in hereditary non-polyposis colorectal cancer families with a MSH2, MLH1, or MSH6 mutation. J Med Genet 39:833-837

40. van Oostrom I, Meijers-Heijboer H, Duivenvoorden HJ et al (2007) Family system characteristics and psychological adjustment to cancer susceptibility genetic testing: a prospective study. Clin Genet 71:35-42

41. Hallowell N, Foster C, Eeles R et al (2004) Accommodating risk: responses to BRCA1/2 genetic testing of women who have had cancer. Soc Sci Med 59:553-565

42. Rini C, Jandorf L, Valdimarsdottir H et al (2008) Distress among inflammatory bowel disease patients at high risk for colorectal cancer: a preliminary investigation of the effects of family history of cancer, disease duration, and perceived social support. Psychooncology 17:354-362

43. Audrain J, Schwartz MD, Lerman C et al (1997) Psychological distress in women seeking genetic counseling for breast-ovarian cancer risk: the contributions of personality and appraisal. Ann Behav Med 19:370-377 